\title{
Method for Calculating the Shape of Rolls for Helical Rolling
}

\author{
Sergey Gorbatyuk ${ }^{1, a}$, Boris Belelyubskii ${ }^{2, b^{*}}$, Aleksei Karfidov ${ }^{1, c}$ and \\ Sergey Snitko ${ }^{3, d}$ \\ ${ }^{1}$ National University of Science \& Technology MISIS, Leninskiy Prospekt 4, Moscow, Russia \\ ${ }^{2}$ Moscow Polytechnic University, Bolshaya Semyonovskaya str. 38, Moscow, Russia \\ ${ }^{3}$ Donetsk National Technical University, Shybankova Square 2, Pokrovsk, Ukraine \\ asgor02@mail.ru, bnis_mgvmi@mail.ru, ca.korf@mail.ru, dsnitko_sa@mail.ru
}

\section{Keywords: Helical Rolling, Shape of Rolls, Calculation Method, Deformation Zone}

\begin{abstract}
The paper is devoted to solving the problem of determining the shape of the rolls of helical rolling mills, depending on the specified profile of the deformation zone. A universal calculation method has been proposed, thanks to which it is possible to determine the shape of the working surface of a roll for all types of helical rolling mills (with mushroom-shaped, cup-shaped, barrel-shaped and disc rolls), any relative arrangement of the rolling axis and rolls axes, and various locations of the deformation zone on the rolling axis. The proposed method is implemented as a standalone exe-application with a simple intuitive interface. The application allows you to output the calculation results into txt-files, which can then be imported into CAD systems to create $3 \mathrm{D}$ roll models.
\end{abstract}

\section{Introduction}

Recently, the development of different industry sectors [1-11] requires the solution of various technological production problems [12-22] and also increases the requirements for the efficiency and quality of production technologies [23-30]. One of the most promising and profitable methods to produce high-quality seamless pipes and rods is helical rolling.

In helical rolling, metal deformation occurs between obliquely located rolls, the axes of which are inclined relative to the rolling axis by a certain angle. Points on the surface of the billet move along a helical line, performing both rotational and translational movements. This method of metal forming is widely used for the manufacture of products in the form of bodies of revolution (balls, axes, pipes, etc.)

When considering many issues related to the helical rolling process, geometric parameters are the basis. This is explained by the fact that the shape and size of the deformation zone significantly affect the conditions of rolling, the required shape of the rolls, etc.

Helical rolling mills are generally classified according to the shape of the work rolls into four main types (figure 1): $a$ - with barrel-shaped rolls, $b$ - with mushroom-shaped rolls, $c$ - with cupshaped rolls, $d$ - with disc rolls.

\section{Calculation model of the geometric parameters of the helical rolling process}

The calculation method is based on the description of the relative position of the rolling and roll axes by the values of the angle $\alpha$ and the distance $\rho$ between them (figure 2).

This was done because during helical rolling the rolling axis and roll axis are skew lines, the relative position of which is uniquely determined by the values of the angle and the distance between them. Also, this approach is interesting in that $\alpha$ and $\rho$ do not depend on the method of adjusting the work rolls and, therefore, are convenient for analysing processes in stands of various designs. 


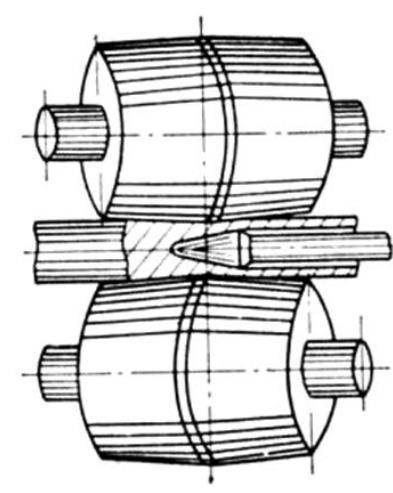

$a$

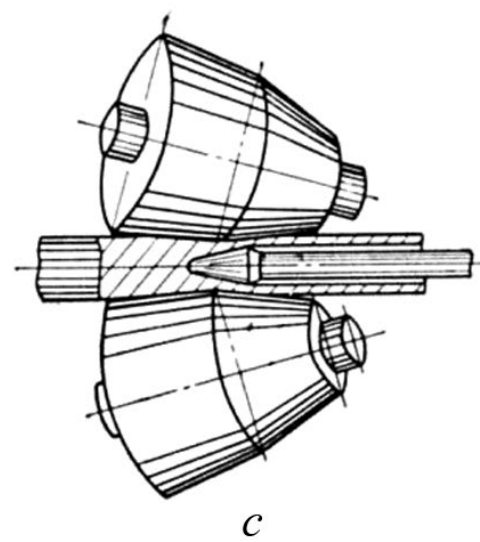

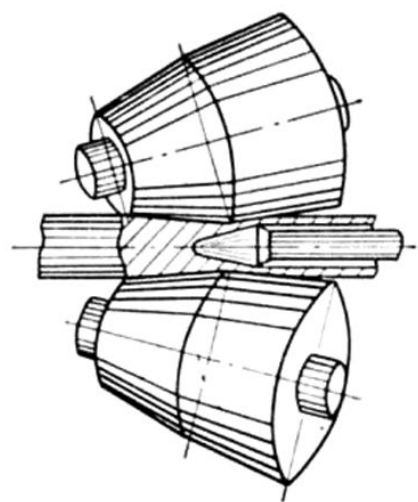

$b$

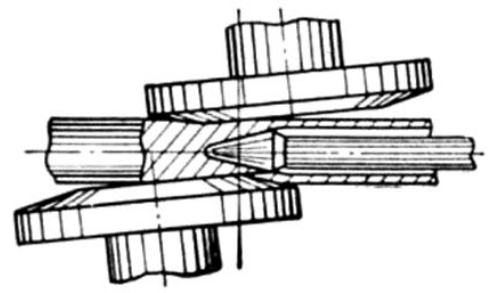

$d$

Fig. 1. Types of rolls for helical rolling:

a - barrel-shaped, b - mushroom-shaped, c - cup-shaped, d - disc rolls.
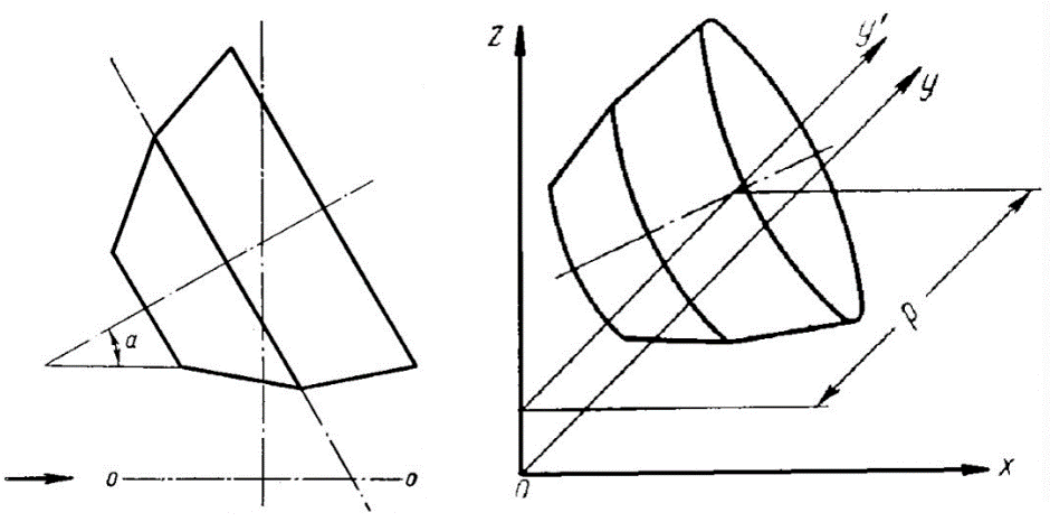

Fig. 2. Parameters of the relative position of the rolling and roll axes.

Thus, if we introduce the assumption that each $i$-th section of the deformation zone is processed by the $i$-th section of the roll, then to calculate the exact values of the roll radius we need to know: $\alpha$ - angle between rolling and roll axes; 
$\rho$ - distance between rolling and roll axes;

$x_{i}$ and $y_{i}$-coordinates of the points of the deformation zone.

For a given section of the roll, the roll radius is gradually increased by the iterative method, and the condition is checked whether the points of the circle formed by this radius are outside the billet

$$
\left\{\begin{array}{l}
\Delta Z \leq\left|Z_{\text {roll }}\right| \\
\Delta Y \leq\left|Y_{\text {roll }}\right|
\end{array}\right.
$$

As soon as the condition is met, the calculation will be interrupted.

Figure 3 represents a diagram that shows that for all points lying outside the billet, either $\Delta Y>$ $Y_{\text {roll, }}$, or $\Delta Z>Z_{\text {roll }}$. Only for one point of the circle $\Delta Y$ will be equal to $Y_{\text {roll }}$, and $\Delta Z$ will be less than $Z_{\text {roll }}$, thus, at this point the condition will be fulfilled and the calculation for this section will be interrupted. The smallest possible radius at which the condition is satisfied on the entire circle will be the necessary one.

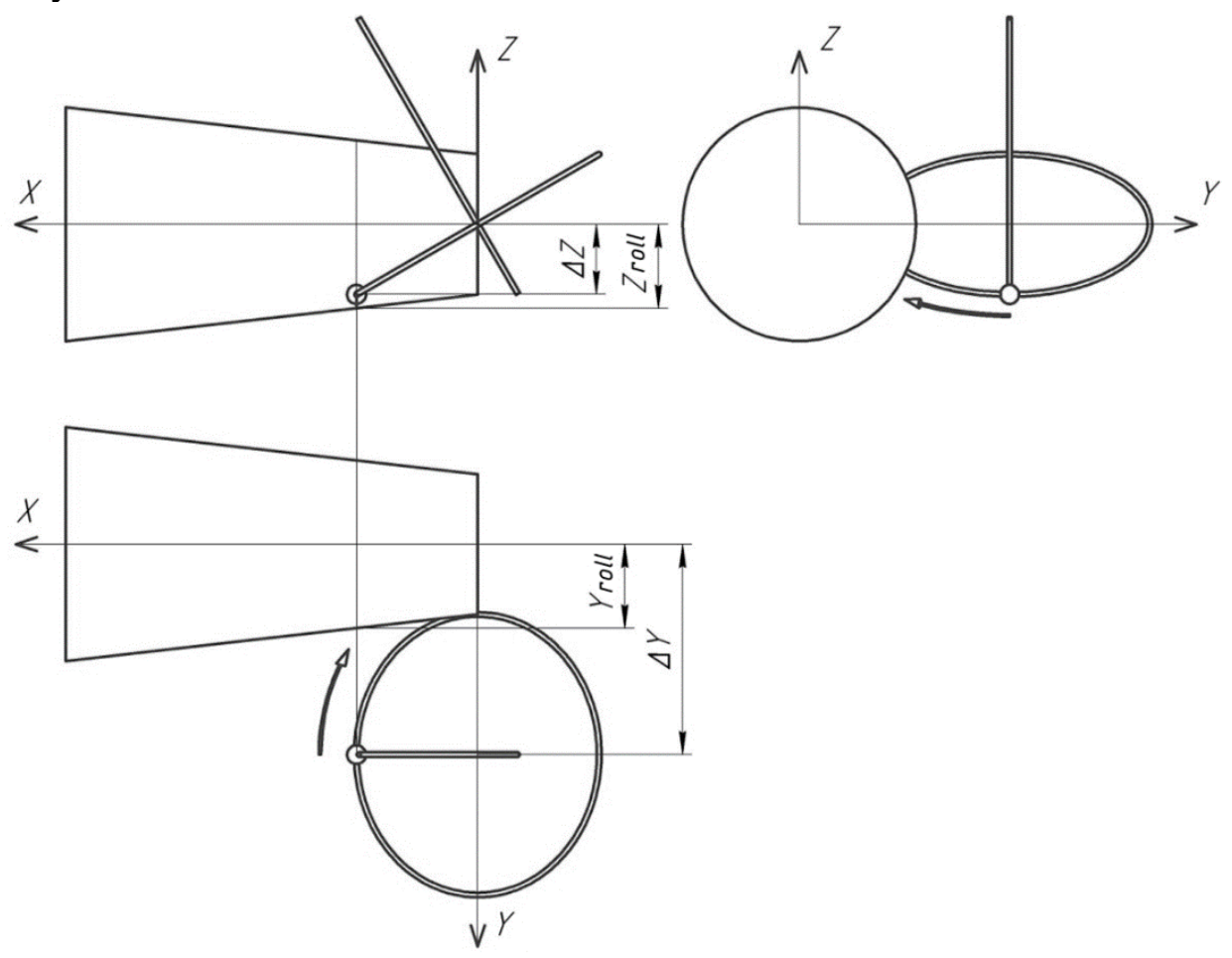

Fig. 3. 2D-scheme of calculation method.

Figure 4 shows the current point on the circle with coordinates $X_{0}, Y_{0}, Z_{0}$, and the arrow shows the direction of reference. The roll radius $R$ increases until one of the points of the circumference touches the surface of the billet. 


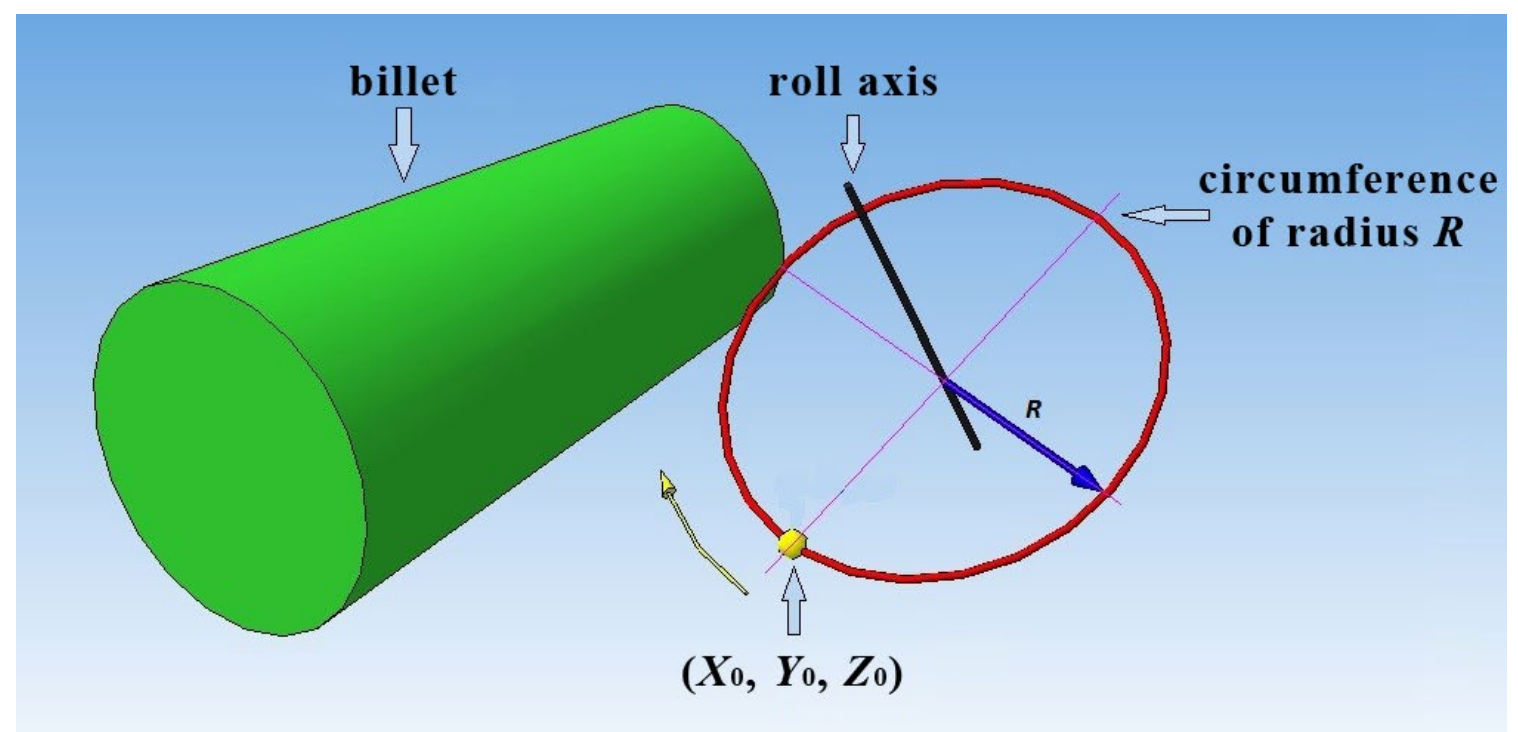

Fig. 4. 3D-scheme of calculation method.

It is important to note that, firstly, the calculation is performed for each section of the roll, and not for the deformation zone, which makes it possible to get rid of additional transformations in the transition from the coordinates associated with the rolling axis to the coordinates associated with a roll axis. Secondly, a different mathematical model is used, based on simple formulas, which makes it possible to exclude errors of the roll caliber at values of $\alpha>60^{\circ}$ and the correction of the deformation zone associated with these errors, thus, the roll bends around the billet without penetrating anywhere ... And, thirdly, this method is suitable for constructing rolls of any type of mill, including even the cases of $\alpha=0^{\circ}$ and $\alpha=90^{\circ}$.

\section{Application for calculating the shape of rolls}

To implement the computational method on a computer, it was decided to use Microsoft Visual Studio 2010 with .NET Framework 4.0 as a programming environment, and C\# as a language. All this allowed us to create an application with an intuitive interface

The basic procedure for the program:

1. The values of $\alpha$ and $\rho$ and the geometry of the deformation zone profile are specified.

2. The necessary calculations are made: defining the boundaries of the roll and checking the data for erroneous values.

3. The $i$-th section of the roll is taken.

4. The radius of the roll in this section is calculated by the iterative method.

5. A calculation is made for each next section of the roll.

6. Data processing and output is in progress.

After entering the required data, pressing the "Roll calculation" button starts the calculation process. Progress will be reflected to the left of the button - in the progress bar. At the end of the calculation, a folder with calculation txt-files opens. The resulting txt-files can be used by CADsystems as input data for modeling (figure 5). 


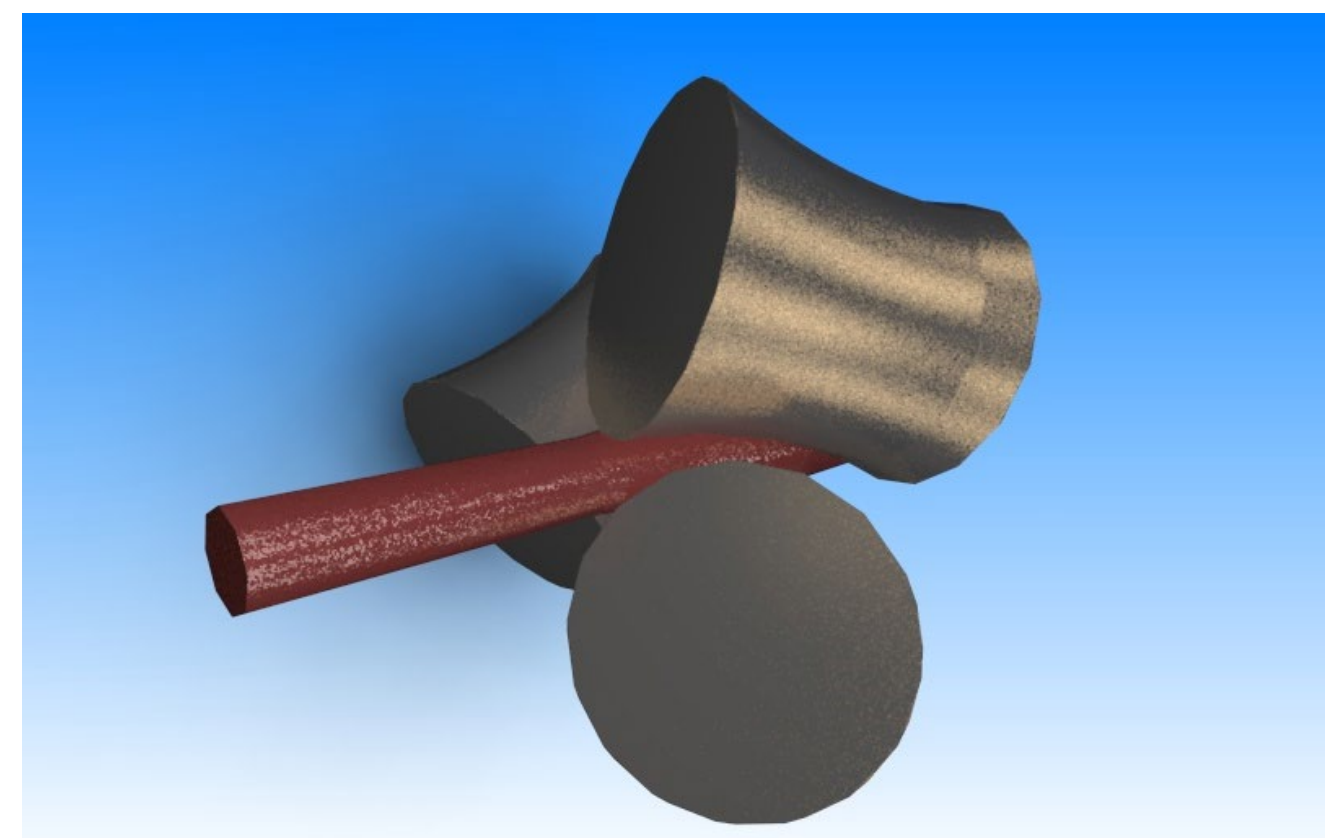

Fig. 5. Visualization of the rolling process of a $6 \mathrm{~mm}$ bar obtained using the application and CAD-system KOMPAS-3D V13.

\section{References}

[1] S. Bratan, S. Roshchupkin, P. Novikov, Modeling the Grinding Wheel Working Surface State, Procedia Engineering 206 (2017) 1419-1425. https://doi.org/10.1016/j.proeng.2017.10.655

[2] Y. Gutsalenko, S. Bratan, S. Roshchupkin, V. Dyadichev, S. Menyuk, Investigation of the Structure and Properties of Copper-Tin Bonding M2-01 in Diamond Grinding Wheel Introducing Additional Energy in the Form of Electric Discharges into the Processing Zone, Materials Today: Proceedings 11 (2019) 586-590. https://doi.org/10.1016/j.matpr.2019.01.033

[3] S. Bratan, B. Bogutsky, S. Roshchupkin, Development of mathematical model of material removal calculation for combined grinding process, Lecture Notes in Mechanical Engineering 0(9783319956299) (2019) 1759-1769. https://doi.org/10.1007/978-3-319-95630-5_189

[4] S.M. Gorbatyuk, A.N. Pashkov, I.G. Morozova, O.N. Chicheneva, Technologies for applying Ni-Au coatings to heat sinks of SiC-Al metal matrix composite material, Materials Today: Proceedings 38 (2020) 1889-1893. https://doi.org/10.1016/j.matpr.2020.08.581

[5] I.I Valiullin, O.A. Kobelev, M.G. Naumova, I.G. Morozova, A.N. Pashkov, V.A. Nagovitsyn, K.V. Goloshchapov, Application of a Discrete Double-Row Scraper Cleaner as an Efficient Procedure of Cleaning of Belt Conveyors Aimed at Transporting Bulk Materials, Metallurgist 64(11-12) (2021) 1340-1346. https://doi.org/10.1007/s11015-021-01124-X

[6] A.D. Bardovsky, S.M. Gorbatyuk, S.V. Albul, N.V. Gorbatyuk, Optimization of Process Flow Diagrams for Processing of Mineral Wastes, Metallurgist 65(3-4), (2021) 465-472. https://doi.org/10.1007/s11015-021-01181-2

[7] V.E. Kondratenko, V.V. Devyatiarova, S.V. Albul, D.S. Kartyshev, Improving methodology for calculating scaffolding formwork of monolithic slabs in building constructions, 
IOP Conference Series: Materials Science and Engineering 971(5) (2020) 052037. https://doi.org/10.1088/1757-899X/971/5/052037

[8] L.V. Sedykh, S.V. Albul, D.B. Efremov, M.A. Sukhorukova, Application of additive technologies for manufacturing a wear-resistant steel pipe outlet, IOP Conference Series: Materials Science and Engineering 971(2) (2020) 022002. https://doi.org/10.1088/1757899X/971/2/022002

[9] V.E. Kondratenko, V.V. Devyatiarova, S.V. Albul, L.M. Valeeva, Method of calculating volumetric scaffold of monolithic slab formwork, IOP Conference Series: Materials Science and Engineering 971(5) (2020) 052036. https://doi.org/10.1088/1757-899X/971/5/052036

[10] A. Keropyan, S. Albul, A. Zarapin A, Problem of Increasing Tractive Effort of Railway Locomotives in Conditions of Arctic and Continental Shelf Regions, Lecture Notes in Mechanical Engineering (2020) 651-658. https://doi.org/10.1007/978-3-030-22063-1_69

[11] G. Sergey, E. Dmitriy, A. Sergei, K. Natalya, The effect of the deformation method of the billets on mechanical properties of molybdenum bars and wire, Key Engineering Materials 864 KEM (2020) 204-210. https://doi.org/10.4028/www.scientific.net/KEM.864.204

[12] V.A. Osadchiy, S.V. Albul, N.S. Kuprienko, N.L. Kirillova, Future developments of a roll forming mill design algorithm, IOP Conference Series: Materials Science and Engineering 709(3) (2020) 044079. https://doi.org/10.1088/1757-899X/709/4/044079

[13] O.A. Kobelev, S.V. Albul, N.L. Kirillova, Research and development of broaching methods on mandrel of large-sized pipe forgings, IOP Conference Series: Materials Science and Engineering 709(4) (2020) 044104. https://doi.org/10.1088/1757-899X/709/4/044104

[14] O. Kobelev, S. Albul, N. Kirillova, Particularities of Calculating Temperature Fields of Large Forging Billets, Lecture Notes in Mechanical Engineering (2021) 797-805.

https://doi.org/10.1007/978-3-030-54814-8_92

[15] A.V. Aldunin, L.S. Kokhan, S.A. Guzenkov, B.F. Belelyubskii, Temperature of working rollers in hot strip-rolling mills, Steel in Translation 39(9) (2009) 751-754.

https://doi.org/10.3103/S0967091209090071

[16] O.E. Kozyreva, N.I. Volgina, B.F. Belelyubskii, Characterization of flawing on feather surface of low pressure compressor blades from VT-3 titanium alloy, IOP Conference Series: Materials Science and Engineering 747(1) (2020) 012006. https://doi.org/10.1088/1757899X/747/1/012006

[17] A. Gerasimova, B. Belelyubskii, Production Engineering of Parts by Cold Stamping, IOP Conference Series: Earth and Environmental Science 459(6) (2020) 062095.

https://doi.org/10.1088/1755-1315/459/6/062095

[18] V.A. Artyukh, V.N. Borsch, V.S. Yusupov, S.Y. Zhuk, V.A. Zelensky, G.Y. Lazarenko, B.F. Belelyubsky, Peculiarities of a Solid-Phase Method for the Production of Al-Fe/SiO2 and Al-Co/SiO2 Powder Catalysts, Inorganic Materials: Applied Research 11(3) (2020) 709-712. https://doi.org/10.1134/S2075113320030041

[19] L. Jiawen, S. Timushev, D. Klimenko, A. Krivenko, Modeling pressure pulsation fields in a screw centrifugal pump, Proceedings of the 26th International Congress on Sound and Vibration, ICSV 2019 (2019) 
[20] A.M. Keropyan, D.A. Kuziev, A.E. Krivenko, Process Research of Wheel-Rail Mining Machines Traction, Lecture Notes in Mechanical Engineering (2020) 703-709. https://doi.org/10.1007/978-3-030-22063-1_75

[21] D. Kouziyev, A. Krivenko, D. Chezganova, B. Valeriy, Sensing of dynamic loads in the open-cast mine combine, E3S Web of Conferences 105 (2019) 03014. https://doi.org/10.1051/e3sconf/201910503014

[22] A.E. Krivenko, Z.K. Khanh, Influence of power fluid temperature in hydraulics on operating efficiency of hydraulic mining excavators, Gornyi Zhurnal 2020(12) (2020) 78-81. https://doi.org/10.17580/gzh.2020.12.18

[23] A.Y. Albagachiev, A.M. Keropyan, A.A. Gerasimova, O.A. Kobelev, Determination of rational friction temperature in lengthwise rolling, CIS Iron and Steel Review 19 (2020) 33-36. https://doi.org/10.17580/cisisr.2020.01.07

[24] N.A. Chichenev, S.M. Gorbatyuk, M.G. Naumova, I.G. Morozova, Using the similarity theory for description of laser hardening processes, CIS Iron and Steel Review 19 (2020) 44-47. https://doi.org/10.17580/cisisr.2020.01.09

[25] L.L. Betina, A.D. Chursin, A.G. Grigoriants, M.A. Kazaryan, N.A. Lyabin, E.V. Perevedentseva, V.S. Paramonov, V.M. Zharikov, Application of Copper Vapour Lasers in the Dimensional Processing Technology, Lasers in Engineering 13(3) (2003) 167-185.

[26] M.A. Kazaryan, N.A. Lyabin, V.M. Zharikov, Technological systems based on copper vapour laser designed for measurement and material processing, Proc. of SPIE - The Int. Society for Optical Engineering 4900(2) (2002) 1094-1098. https://doi.org/10.1117/12.484509

[27] V.N. Titov, S.D. Saifullaev, M.M. Skripalenko, A.I. Ternovykh, A.A. Sidorov, Using Deform-2d Software to Study Heat-Insulation Materials as Protection of Air Tuyeres Against Burnout, Metallurgist 64(5-6) (2020) 388-395. https://doi.org/10.1007/s11015-020-01007-7

[28] M.M. Skripalenko, O.A. Kobelev, S.D. Sayfullayev, Burnout resistance assessment of air tuyere in blast furnace, IOP Conference Series: Materials Science and Engineering 971(3) (2020) 032033. https://doi.org/10.1088/1757-899X/971/3/032033

[29] S.M. Gorbatyuk, S. Sayfullaev, O.A. Kobelev, M.A. Sukhorukova, Choice of thermal insulation for burnout protection of a blast furnace blast tuyere, Materials Today: Proceedings 38 (2021) 1388-1391. https://doi.org/10.1016/j.matpr.2020.08.110

[30] A.S. Budnikov, E.A. Kharitonov, A.S. Aleshchenko, R.V. Iskhakov, Effect of plugless deformation in screw rolling three-roll mill on the change of tube wall thickness, Chernye Metally 2019(12) (2019) 41-45. 